\title{
Correction to: Investigating the bioenergy potential of invasive Reed Canary (Phalaris arundinacea) through thermal and kinetic analyses
}

\author{
Hesham Alhumade ${ }^{1,2} \cdot$ Muhammad Sajjad Ahmad $^{3,4} \cdot$ Emanuele Mauri $^{5} \cdot$ Yusuf Al-Turki $^{6} \cdot$ Ali Elkamel $^{4}$
}

(c) Springer-Verlag GmbH Germany, part of Springer Nature 2021

\section{Correction to: Biomass Conversion and Biorefinery https://doi.org/10.1007/s13399-021-01664-x}

The original version of this article was lacking a reference to a previous study [2] conducted on the same sample and published by the same authors, from which part of the text from the characterization section was reused without citation.

The original article [1] has been updated to include this citation.

\section{References}

1. Alhumade, H., Ahmad, M.S., Mauri, E. et al. Investigating the bioenergy potential of invasive Reed Canary (Phalaris arundinacea) through thermal and kinetic analyses. Biomass Conv. Bioref. (2021). https://doi.org/10. 1007/s13399-021-01664-x

2. Alhumade, H., Ahmad, M.S., Çakman, G. et al. Investigation of pyrolysis kinetics and thermal behavior of Invasive Reed Canary (Phalaris arundinacea) for bioenergy potential. Jour. Analytic/Applied Pyrolys (2019). https://doi.org/ 10.1016/j.jaap.2019.04.018

Publisher's note Springer Nature remains neutral with regard to jurisdictional claims in published maps and institutional affiliations.

The original article can be found online at https://doi.org/10.1007/ s13399-021-01664-x.

\section{Ali Elkame}

aelkamel@uwaterloo.ca

1 Department of Chemical and Materials Engineering, Faculty of Engineering, King Abdulaziz University, Jeddah 21589, Saudi Arabia

2 Center of Research Excellence in Renewable Energy and Power Systems, King Abdulaziz University, Jeddah 21589, Saudi Arabia

3 Department of Chemical Engineering, Hebei University of Technology, Tianjin, China

4 Department of Chemical Engineering, University of Waterloo, Waterloo, Canada

5 Department of Engineering, Università Campus Bio-Medico Di Roma, via Álvaro del Portillo 21, 00128 Rome, Italy

6 Department of Electrical and Computer Engineering, Faculty of Engineering, King Abdulaziz University, Jeddah 21589, Saudi Arabia 